\title{
TUNING MAZDA B6 ENGINE FOR SPORTS COMPETITIONS
}

\author{
Ing. LUKÁCS E. ${ }^{1}$, doc. Ing. POLÓNI M. CSc. ${ }^{2}$ \\ ${ }^{1}$ Dolné Zahorany 60, 98542 Vel'ké Dravce, lukacserik@gmail.com \\ ${ }^{2}$ Strojnícka fakulta STU v Bratislave, marian.poloni@stuba.sk
}

\begin{abstract}
Improving output parameters of the Mazda B6 combustion engine from the vehicle Mazda 323 for amateur "hill climb" and "rally" competitions has been analysed. Tuning of such an engine for sport competitions means the optimisation of its parameters at the lowest possible economic costs, within the revolution range 4000 - $6000 \mathrm{~min}^{-1}$, where the engine during competition works most often. With the help of the program Lotus Engine Simulations, the construction of the exhaust manifold has been optimised, together with valve timing and other adjustments, listed in the work, on output parameters of the engine. The optimum combinations of parameters were experimentally verified on a chassis dynamometer. Final adaptations have led within the previously specified range of revolutions to an improvement between 5 and $22 \%$ in power and torque.
\end{abstract}

KEY WORDS: tuning of engine, output, $1 D$ simulations

\section{INTRODUCTION}

Engines produced in large quantities for common passenger cars do not often work at full load and maximum RPM's (rotations per minute). That is why the designers are always trying to tune engines to maximize torque at lower or possibly mid RPM's. In the case of sport utilisation of a car, the requirements on the driving unit are different. The combustion engine in this case works almost at full load at high RPM's.

The consumption and harmful emissions of these engines are not so important; however, even newer models of sport cars must be equipped with a sport catalyser. Our aim was to tune the Mazda B6 engine in such a way that the vehicle would reach the best output parameters and the best acceleration properties with respect to RPM, in which the engine most often works during competitions. For the known unchanged gear ratios, we needed to increase the torque at full load, within the revolutions $3500-6000 \mathrm{~min}^{-1}$.

The next rather important tuning requirements were for the minimum financial investments to the engine adjustment. To study the changes of output parameters relative to various adjustments of the engine that had to be done without a great number of experimental verifications, the effects of the changes were studied within the software environment Lotus Engineering Software, simulation instruments of Lotus Engine Simulation (LES), version 5.06h [1].

The stock Mazda B6 engine has the following parameters: non-supercharged, petrol powered, liquid cooled, 4-cylinder engine with a volume of $1597 \mathrm{~cm}^{3}, 78 \times 83.6 \mathrm{~mm}$ bore and stroke, compression ratio of 9:1, 4 valves per cylinder, max. output $65 \mathrm{~kW} / 5300 \mathrm{~min}^{-1}$, max. torque $130 \mathrm{Nm} / 4000 \mathrm{~min}^{-1}$.

\section{ENGINE MODEL IN PROGRAM LES}


First, before any adjustments, the engine was measured on a stand to compare results to any changes. The next task was to model a virtual engine of the Mazda in the aforementioned program LES which is a simulation instrument able to generate complex calculations on parameters for twoand four-stroke non-supercharged or supercharged engines. The program allows for calculations of 1D unsteady flow in the manifold system of the engine, together with solutions of boundary conditions and solutions for gas exchange processes of the combustion.

To find out the precise entry parameters for calculations, the geometry of the intake manifold, valves and many other parts of a totally decomposed engine were measured. The scheme of the engine model in program LES can be seen in Fig. 1. The part on the left represents the intake system and the part on the right represents the exhaust system. Tuning and precision of input data have led to a comparatively good agreement in the course of the torque. The differences between the calculation and the experiment was between $2-8 \%$.

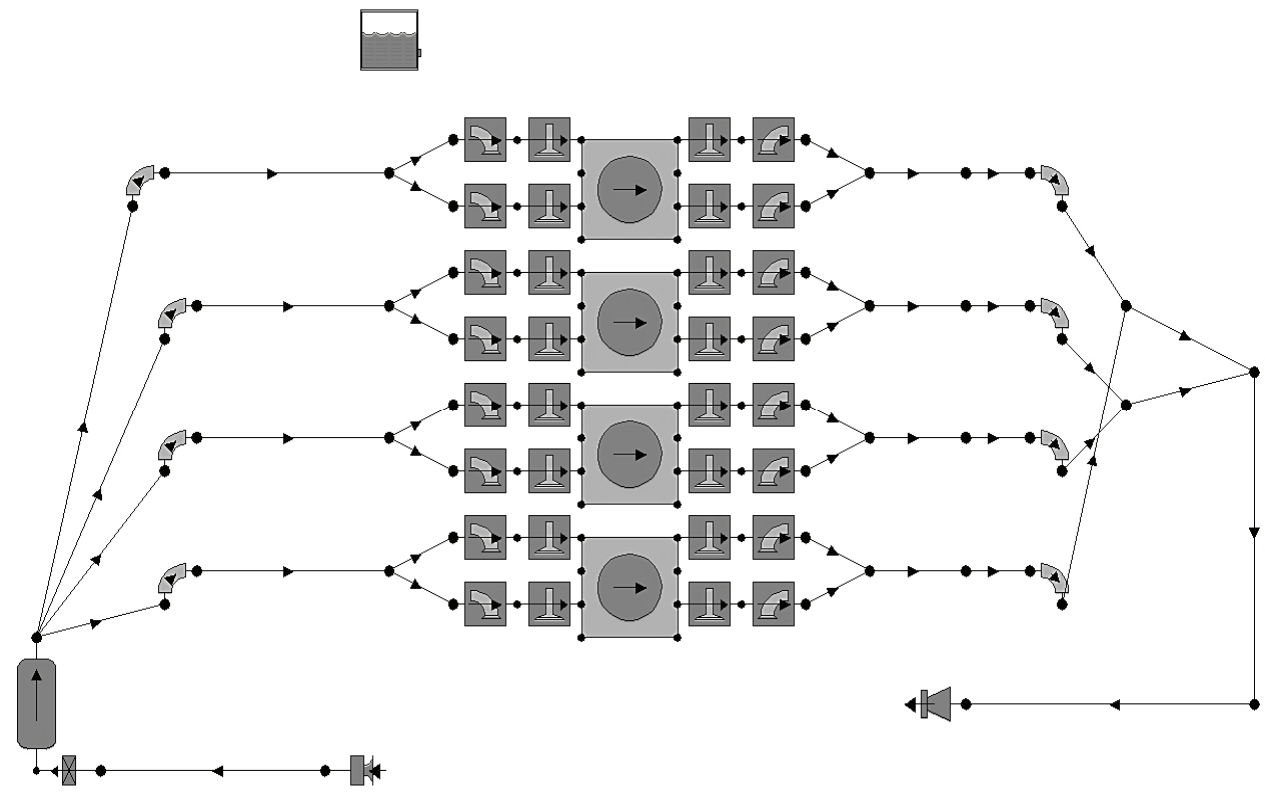

Fig. 1 Engine model in program LES

\section{ADAPTATION OF ENGINE HEAD}

The decisive entry parameters that are necessary for the process of engine modelling are the values of flow coefficients of separate ports together with their valves. To get the best match between calculations and experiments, the values of flow coefficients were gathered experimentally, in a laboratory by standardised procedures [2].

The first modification made to the engine was the enlargement of ports in the engine head, then improvement of irregularities in the passages, and improvement of surface finish (Fig. 2, 3). These changes had a direct effect on the values of flow coefficients and thus the modified head, or ports, flow properties were measured. The percentage of increased flow coefficients was between 1 $-10 \%$ both for the intake and exhaust port. 

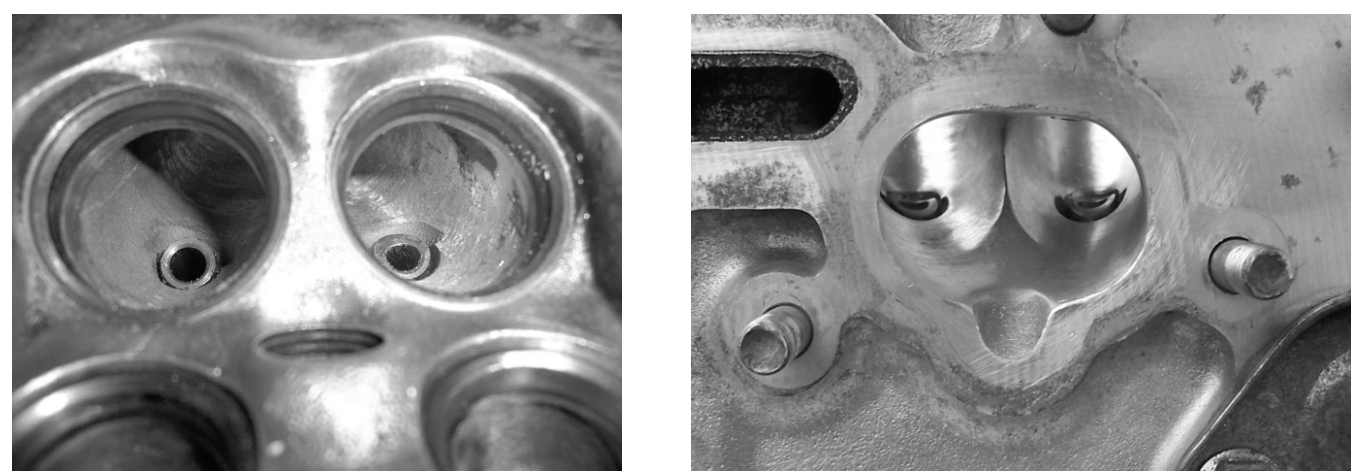

Fig. 2 Intake and exhaust ports before modification Fig. 3 Intake port after modification

The increased flow coefficients manifested in the program LES have a slightly better value of filling efficiency at higher revolutions of the engine. Particularly, the adaptation of the intake and exhaust ports led to an 1 - $5 \%$ increase in torque within the RPM's 4000-6000 $\mathrm{min}^{-1}$.

Further adaptation was focused on increasing the compression ratio of the engine. The increase was realized by decreasing the compression volume by milling away $1 \mathrm{~mm}$ from the head of the cylinders. By this modification the compression ratio changed from 9.0:1 to 9.6:1, which means an increase of maximum mean effective pressure during the process of combustion. From the values calculated by the program LES the enhancement of the compression ratio has been found and gives a slight increase $2-3 \%$ of torque within the whole range of engine revolutions.

\section{ADJUSTMENT OF VALVE TIMING}

For the modification of an engine for sport utilisation and for enhanced torque at higher revolutions adjustments to the camshaft play an important role. The angles and the period of opening specific valves in the original, stock camshaft is organised in such a way that the intake valve opens at $6^{\circ}$ before TDC (top dead centre) and closes at $53^{\circ}$ before BDC (bottom dead centre), which means that the intake valve is open throughout $239^{\circ}$ of crankshaft rotation. The exhaust valve is actuated by the same camshaft as the intake valve. The opening period of the exhaust valve starts at $53^{\circ}$ before BDC and closes at $6^{\circ}$ after TDC. In the following text the timing of the valves will be represented in some other way, for example a series-produced cam: 6/53 - 53/6 i.e. timing of intake - exhaust valves. The lift of the intake valve is $7.5 \mathrm{~mm}$ and the exhaust valve is $7 \mathrm{~mm}$.

By modelling, the theoretically ideal timing was prepared for the particular range of revolutions and, most importantly, for the given geometry of manifold system. The values of the timing are: 19/40 - 59/20. Such timing is not possible to reach by "reprofiling" the camshaft or modification of the cam profile. As an engine has just one camshaft to open both the intake and exhaust valves, a shift in the opening of intake valves will influence the opening of the exhaust valves in an undesirable way. A camshaft with the required timing would have to be produced from a new shaft, which is financially expensive and ineffective.

In the end a resulting compromise solution for timing was found: $6 / 53-59 / 20$. The timing of the intake valves remained unchanged. However, the period for which the exhaust valves remained open was changed by reprofiling to $259^{\circ}$. Because the peak of the cam was shifted as a result of grinding the cam by $2^{\circ}$, the time of exhaust valve closing on the crankshaft was shifted to $20^{\circ}$ after TDC. Fig. 4 documents effect of the changes in timing of exhaust valves, port adaptations 
and change of compression ratio on torque, gained from the model. The percentage of enhanced torque as a result of these adaptations is from 4 to $16 \%$ at revolutions over $4000 \mathrm{~min}^{-1}$.

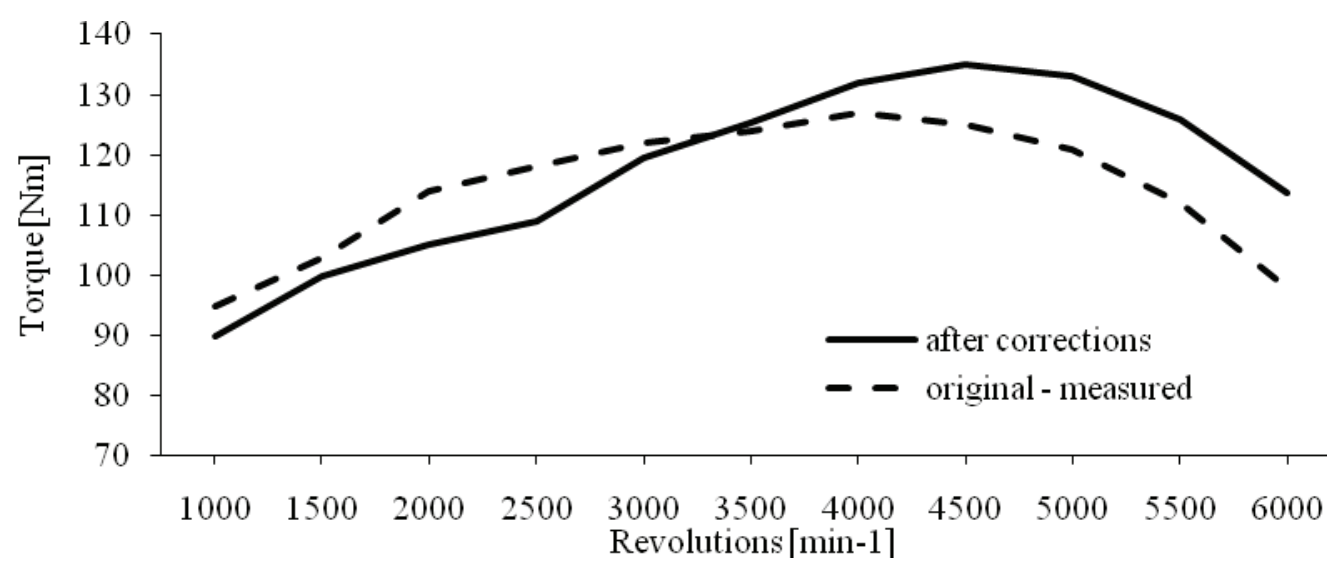

Fig. 4 Effects of port adaptations, changes of compression ratio and timing of exhaust valve on engine torque

\section{TUNED EXHAUST MANIFOLD}

The exhaust manifold in which separate lines of the manifold are joined to two, and then later to one common manifold, has a positive impact on gas exchange at higher revolutions [3]. The effect of the exhaust manifold, model 4-2-1 (Fig. 5) on parameters of the engine were also optimised within the program LES. As a result of the optimisation of diameters and lengths of single branches of the exhaust pipe system, a considerable increase in the torque were found after the application of the modifications, within the required range of revolutions. It is visible in Fig. 6 where there is a comparison of torques (both curves gained from model) of the adapted engine having different exhaust systems. The exhaust system 4-2-1 increased the engine torque by positively influencing the processes of gas exchange in particular cylinders, which has led to increased filing efficiency of the engine at higher revolutions. So somewhat decreased amount of residual gases in particular cylinders and a better filling-up with fresh mixture was reflected in a maximum of $7 \%$ increase in the torque.

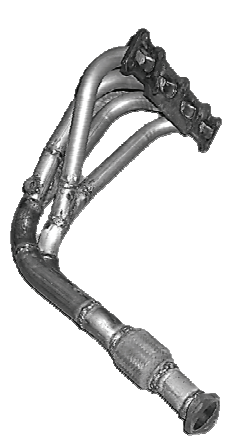

Fig. 5 Exhaust manifold, model 4-2-1

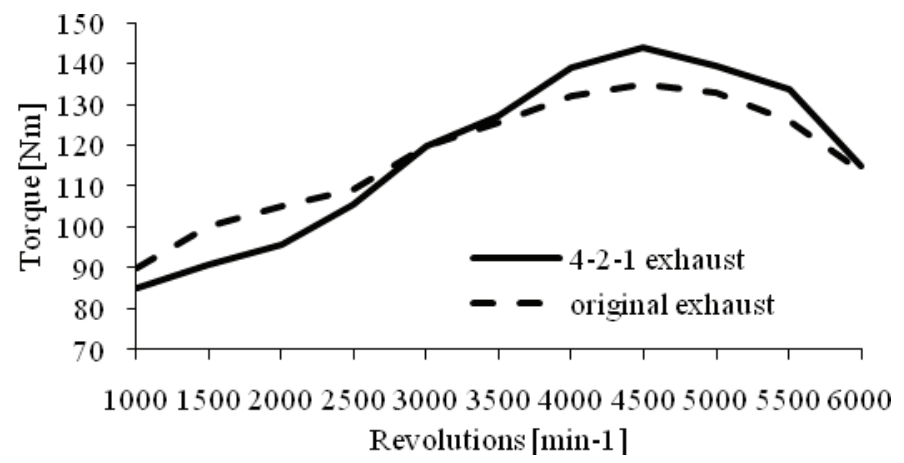

Fig. 6 Effect of exhaust manifold on adapted engine 


\section{RESULTS}

The measurements on a stand were verified by results gained from the model of the whole engine in the program LES, including the above-mentioned adaptations. The measurements before and after adaptations were performed on the same engine as the mistakes in measurements had to be minimised. Fig. 7 compares the curves of torque of serially produced engine, tuned engine, and the simulation model engine, i.e. calculations from LES.

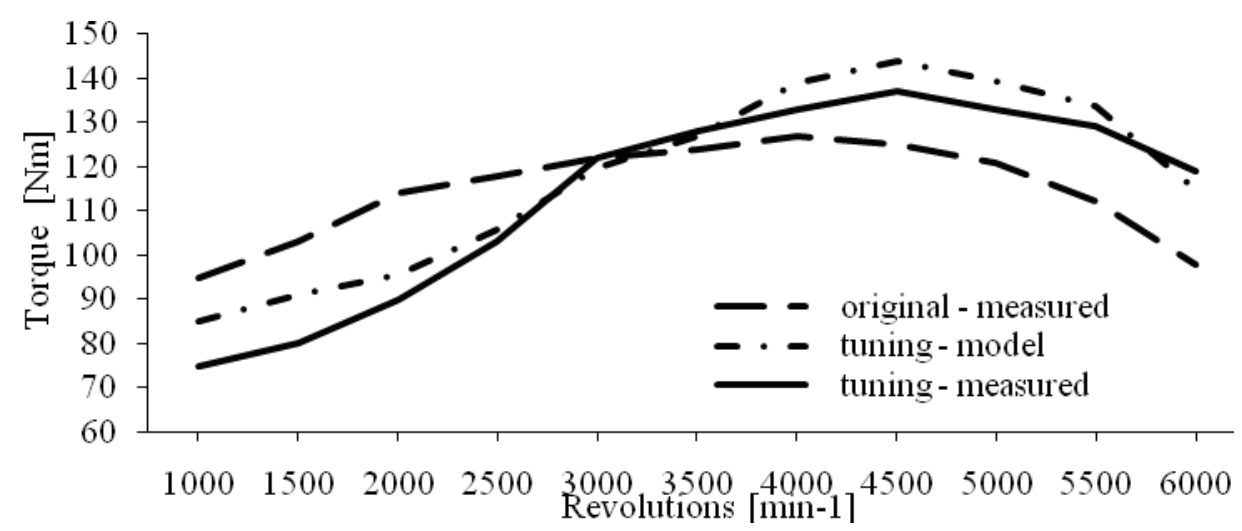

Fig. 7 Curves representing torques of serially produced and adapted engine

As it was mentioned in the introduction to this article, the aim of the tuning was to reach the best power parameters in the RPM range $4000-6000 \mathrm{~min}^{-1}$. This aim has been achieved as Fig. 7 documents. The percentage difference between the model and the measured engine is maximum $13 \%$, but only at revolutions between 1000 and $1500 \mathrm{~min}^{-1}$. In other ranges it fluctuates between 2 and $8 \%$. Both curves clearly show a good agreement between the measured and calculated torque in the whole range of revolutions. Fig. 8 shows an increase in the output of the combustion engine after adaptations, i.e. tuning.

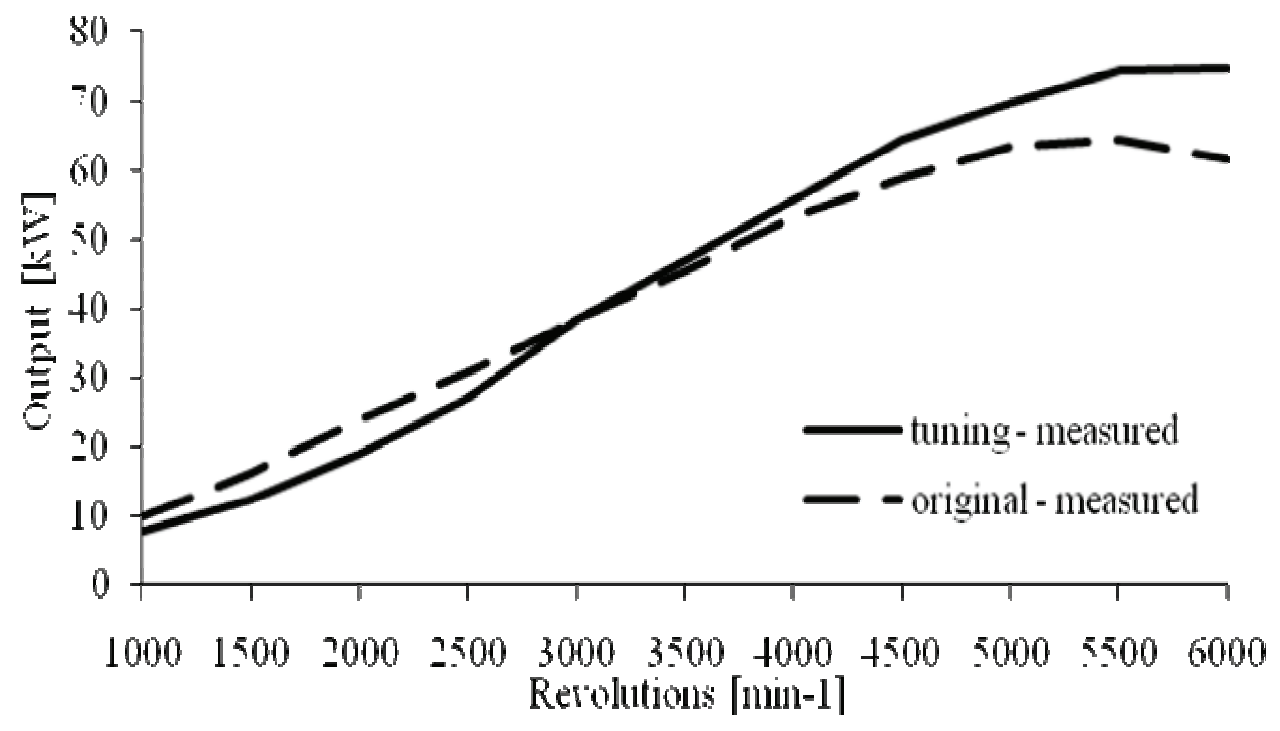


Fig. 8 Curves of output for the stock engine and tuned engine

The final parameters of the tuned engine are:

Maximum torque: $137 \mathrm{Nm}$ at $4500 \mathrm{~min}^{-1}$, representing an increase of maximum torque by $8 \%$.

Maximum output: $75 \mathbf{~ k W}$ at $6000 \mathrm{~min}^{-1}$, increase of maximum output is $15 \%$.

\section{CONCLUSION}

The increase in maximum output parameters of the Mazda B6 engine for sport utilisation, in the working range of 4000-6000 $\mathrm{min}^{-1}$ in comparison to the original setting, has been reached. The output and torque improved between 5 - $22 \%$ in the given range of revolutions. The acceleration properties of the car have been considerably improved. If the economy aspects are considered, the improvement of parameters has been gained even without tuning the intake manifold, which opens some possibilities for further improvement of the values on power parameters. However, these positive changes occur at the expense of approximately $20 \%$ decrease in the output parameters at low revolutions (1000-3000 $\left.\mathrm{min}^{-1}\right)$, which the engine in sport occasions uses very rarely. The modifications of the engine in the program LES have proved that $1 \mathrm{D}$ modelling is suitable for optimisation of input parameters of the engine.

\section{ACKNOWLEDGEMENT}

This work was supported by the Slovak Research and Development Agency under the contract No. APVV-0270-06 and by the Scientific Grant Agency under the contract No. VEGA $1 / 0024 / 09$.

\section{REFERENCES}

[1] Lotus Engineering Software, Lotus Engine Simulation www.lotuscars.com

[2] POLÓNI M. a kol.: Meranie prietokových súčinitel’ov hláv valcov motora ZETOR. Výskumná správa KSM - VS - 89, Strojnícka fakulta STU v Bratislave, 1982 (In Slovak)

[3] APFELBECK L.: Wege zum Hochleistungs-Viertaktmotor, Motorbuch, 1997, ISBN: 3879435782 (In German) 